sensitive area of the cerebral cortex is being stimulated through the thickest part of the cranium, and to produce a fit more electrical energy is required.

Our findings highlight the differences and conflicts between clinical judgment and research findings and emphasise the need for more intensive research into the value of this important and widely used treatment. The views expressed differ from those in the memorandum of the Royal College of Psychiatrists.

We thank Dr Guy Edwards for his most helpful guidance and criticism, Mrs Sheila Masterman for her help with the statistical analysis, and Mrs Brenda Stringer and Mrs Gail Frankowski for their secretarial help.

\section{References}

${ }^{1}$ Royal College of Psychiatrists, British fournal of Psychiatry, 1977, 131, 261.

2 Tien, H C, Michigan Medicine, 1975, 74, suppl No 15, p 251.

${ }^{3}$ Frankel, F H, et al, Massachusetts fournal of Mental Health, 1973, 3, 3.
4 Klein, D F, Psychopharmacology Bulletin, 1975, 11, suppl No 3, p 3.

5 Hobson, R F, fournal of Neurology, Neurosurgery and Psychiatry, 1953, 16, 275.

6 Roberts, J M, Fournal of Mental Science, 1959, 165, 693.

' Hamilton, M, and White, J, fournal of Mental Science, 1960, 106, 1031.

${ }^{8}$ Carney, M W, et al, British fournal of Psychiatry, 1965, 111, 659.

${ }^{9}$ Mendels, J, American Fournal of Psychiatry, 1967, $124,153$.

10 Fleminger, J J, et al, American fournal of Psychiatry, 1970, 127, 430.

11 Miller, E, British Fournal of Psychiatry, 1967, 113, 301.

12 Janis, I L, Fournal of Nervous and Mental Disease, 1950, 111, 359.

13 Brenglemann, J C, The Effect of Repeated Electro-shock on Learning in Depressives. Berlin, Springer-Verlag, 1959.

14 Cronholm, B, and Blomquist, C, Acta Psychiatrica Scandinavica, 1959, 34, 18.

15 Cronholm, B, and Molander, L, Acta Psychiatrica Scandinavica, 1957, 32, 280.

16 Cameron, D E, Comprehensive Psychiatry, 1960, 1, 26.

17 Wilcox, P H, Diseases of the Nervous System, 1946, 194, 201.

18 Goldman, D, Fournal of Nervous and Mental Disease, 1949, 110, 36.

10 Lancaster, N P, et al, fournal of Mental Science, 1958, 104, 221.

${ }^{20}$ Friedman, E, and Wilcox, P M, Fournal of Nervous and Mental Disease, $1942,96,56$

(Accepted 13 March 1979)

\title{
Campylobacter enteritis associated with consumption of unpasteurised milk
}

\author{
D A ROBINSON, W J EDGAR, G L GIBSON, A A MATCHETT, L ROBERTSON
}

British Medical fournal, 1979, 1, 1171-1173

\section{Summary and conclusions}

In October and November 1978 two outbreaks of enteritis occurred in the north of England. Symptoms lasted two to over eight days but in no case necessitated admission to hospital. Faecal specimens from most of the patients were found to contain thermophilic Campylobacter sp. Inquiry disclosed that all patients had consumed unpasteurised milk from local farms. Examination of rectal swabs from the cattle concerned and milk socks yielded strains of Campylobacter sp indistinguishable from those isolated from the patients. It was therefore concluded that, since campylobacters are not known to be excreted in milk, faecal contamination of the milk had probably occurred and had led to these outbreaks.

Evidence suggests that thermophilic Campylobacter sp is an occasional contaminant of milk. So long as unpasteurised milk continues to be distributed further outbreaks will probably occur.

Public Health Laboratory, Withington Hospital, Manchester M20 8LR

D A ROBINSON, MD, MSC, epidemiologist

Bradford Royal Infirmary, Bradford, Yorks BD8 7QF

W J EDGAR, MD, FRCPATH, consultant microbiologist

Public Health Laboratory, Leeds

G L GIBSON, MD, FRCPATH, director

Arnside, Cumbria

A A MATCHETT, MB, CHB, general practitioner

Public Health Laboratory, Preston

L ROBERTSON, BM, FRCPATH, director

\section{Introduction}

In the past year two outbreaks of campylobacter enteritis have been described in which the circumstances suggested that milk was the vehicle of transmission. ${ }^{12}$ We report two further such outbreaks.

\section{Cumbria outbreak}

Between 10 and 20 October 1978, 63 people presented to general practitioners in Arnside and Milnthorpe (Cumbria) with symptoms mainly consisting of abdominal pain and diarrhoea. Fifty-seven of the patients lived in Arnside village; three in Storth, a village two miles $(3 \mathrm{~km})$ to the east; and three, all in one family, in Milnthorpe, a town some five miles further inland. All but one of the patients complained of diarrhoea, and $48(76 \%)$ also had cramping abdominal pain. The faeces were watery, offensive, and did not contain visible blood. Eight patients $(13 \%)$ also complained of headache, $6(10 \%)$ of vomiting, and $4(6 \%)$ of fever, and in one case there was a macular, erythematous rash. The symptoms lasted on average two to three days and were never severe enough to warrant admission to hospital. The patients were aged 8 months to 78 years, and no age group was predominant. The cases occurred in a single wave with onsets between 8 and 13 October (see table), and there was no evidence of secondary transmission within affected families.

Dates of onset of 63 cases in Cumbria outbreak

\begin{tabular}{lllllllrlrrr}
$\begin{array}{l}\text { Date (October) } \\
\text { No of cases }\end{array}$ &. &.. &.. &.. &.. & 8 & 9 & 10 & 11 & 12 & 13 \\
\hline
\end{tabular}

\section{INVESTIGATION}

Thermophilic Campylobacter sp was isolated from the faeces of 38 of the 53 patients tested. No other pathogens were detected. Inquiries about the source of supply of food, water, and milk to all patients disclosed that all had regularly consumed unpasteurised milk obtained from a local farm. The farm had a milking herd of 85 cows producing 
150 gallons (680 1) daily. Milking was carried out mechanically, and the milk was chilled rapidly to about $5^{\circ} \mathrm{C}$. About $60 \%$ of the output was bottled on the premises without pasteurisation and sold through a retailer. The remainder was supplied in bulk to the Milk Marketing Board for pasteurisation. Some $60 \%$ of the households in Arnside and Storth bought unpasteurised milk, the remainder taking pasteurised milk from the same retailer. About 10 gallons (45 1) of unpasteurised milk from the farm was distributed each day in Milnthorpe. Although no specific investigation was made of the population who drank only pasteurised milk, no cases presented from this group.

Milk and milk socks from the farm were examined on the second, third, and fourth days after the occurrence of the last case. No pathogens were isolated. Rectal swabs from the 85 cows were also examined, and thermophilic Campylobacter sp was isolated from nine. None of the animals had been ill in the previous month, and only one had recently come into milk. Campylobacter sp was not isolated from this animal. The strains isolated from patients and cows were biotyped at the bacteriology department, Worcester Royal Infirmary. All of the nine human strains and four of the nine cow strains tested were found to be indistinguishable. Slight variations, which could have been accounted for by experimental differences, were found in other cow strains.

\section{CONCLUSION}

Isolation of a campylobacter from milk or milk socks would have strengthened the epidemiological evidence, but the failure to do so is not surprising. The time distribution of the cases suggests that if milk was the vehicle of infection the contamination that led to the outbreak had occurred during milking on one or two days only. Labour troubles at the farm had caused difficulties with milking a day or two before the onset of the first case, and the cows had remained in the milking parlour for over an hour after milking was finished on that occasion. Possibly faecal contamination of the milk occurred only during this period of disturbed routine. The quantity of milk consumed by patients varied from a few ounces poured over cornflakes to several pints taken straight from the bottle, but no association between dose and clinical severity or duration of incubation was discernible. Nevertheless, the strong correlation between the occurrence of symptoms and the consumption of unpasteurised milk, and the isolation of biotypically indistinguishable organisms in the faeces of the milking herd, suggests that milk was indeed the vehicle.

\section{Bradford outbreak}

Between 1 and 22 November 1978, 14 people with enteritis were notified to the Bradford Environmental Health Division. The first patient became ill on 31 October. All lived in the same area. All had abdominal pain and diarrhoea, two vomited, and some complained of headache and fever. The symptoms lasted from two to over eight days.

\section{INVESTIGATION}

Examination of faeces from the 14 patients yielded thermophilic Campylobacter $\mathrm{sp}$ in 12 . No other pathogens were detected. Inquiries into a possible common source of infection showed that 13 of the patients obtained their regular milk supply, unpasteurised, from one local farm. The fourteenth normally drank pasteurised milk at home but admitted to having bought half a pint $(280 \mathrm{ml})$ of unpasteurised milk, supplied by the same farm, shortly before he became ill. Campylobacter sp was isolated from his faeces.

Faecal specimens were obtained from 26 people who had not had symptoms. These comprised household contacts of patients and the farmer and four members of his family. Campylobacter sp was isolated in four cases, including one of the farmer's daughters. Six dogs in affected households were also tested, and Campylobacter sp was isolated from four. None had been noticed to have loose stools.

The milk supply was investigated by examining the milk socks used at morning and evening milkings from 12 November for 23 days. Campylobacter sp was isolated from socks on two of the 46 occasions, on 22 and 27 November. No campylobacter was isolated from bottled milk at any time. Biotyping at the Worcester Royal Infirmary showed the strains isolated from human faeces and milk socks to be indistinguishable.

\section{CONCLUSION}

Shortly before the outbreak the cattle had suffered from scouring, which was said to be due to their having fed in a field of barley stubble. The scouring might well have increased the chances of milk becoming infected with campylobacters, whether it was caused by extraneous factors in the presence of a pre-existing, symptomless campylobacter infection or whether it was in fact a manifestation of a recent campylobacter infection. It might also explain why this outbreak, unlike the first, apparently resulted from contamination occurring over several days. That Campylobacter sp was isolated from a milk sock 26 days after the occurrence of the first case indicates that the conditions permitting contamination were probably continuing, and had not an order to prevent further sale of the milk been served on 21 November there might well have been further cases.

\section{Microbiological methods}

Since the publication of Skirrow's seminal paper on campylobacter enteritis ${ }^{3}$ the methods described by him for isolating Campylobacter $\mathrm{sp}$ have been widely applied and found to be effective. The isolation of this organism from environmental swabs, from food and milk, and from the faeces of different animals may, however, present problems that require some adaptation of methods, and particularly the use of enrichment media. The following, modified liquid medium ${ }^{4}$ was used successfully to examine the milk socks in the Bradford outbreak: nutrient broth $375 \mathrm{ml}$, blood $25 \mathrm{ml}$, vancomycin $10 \mu \mathrm{g} / \mathrm{ml}$, polymyxin B sulphate $2.5 \mathrm{IU} / \mathrm{ml}$, and trimethoprim lactate $5 \mu \mathrm{g} / \mathrm{ml}$.

\section{Discussion}

The association of campylobacter infection with diarrhoea in cows has been recognised for many years, ${ }^{5}$ and now that this infection has generally been accepted as a zoonosis it is not surprising to find evidence of milk-borne transmission to man. In 1946 Levy $^{6}$ described an outbreak of 357 cases of enteritis in man, in the faeces of a proportion of which a vibrio-like organism was seen by microscopy. From his description of the organism and its cultural characteristics it was probably a campylobacter. Although the organism was neither seen in nor cultured from milk the evidence pointed to contaminated milk from a particular dairy as the source of infection.

We know of no evidence to suggest that campylobacters are excreted in milk, and it seems most likely that faecal contamination was responsible for both outbreaks reported here and for that reported by Levy. In Somerset during the blizzards of 1977-8 an outbreak of campylobacter enteritis occurred after the consumption of milk that had been collected and distributed under extremely difficult conditions, ${ }^{1}$ once again illustrating the association with some sort of breakdown in the usual hygienic routine. That was the first milk-associated outbreak of campylobacter enteritis reported in Europe. A family outbreak in Colorado $^{2}$ also showed features suggesting that milk was the vehicle of transmission, and this was supported by the isolation of a campylobacter from the family's hand-milked house cow. The investigators blamed faecal contamination of the milk during milking.

No work on the infective dose of campylobacters in man has been published, but this is clearly of prime importance in assessing the likelihood of illness resulting from the distribution of contaminated milk. Of similar importance is knowledge of the ability of campylobacters to multiply and survive in milk. Preliminary work on survival times ${ }^{7}$ showed that campylobacters are recoverable from milk stored at $4^{\circ} \mathrm{C}$ for up to 164 days, and for 61 days from milk at room temperature. This makes an interesting contrast with survival in fresh water, which has been timed at 11 and two days respectively at these two temperatures.

The isolation of campylobacters from the faeces of nine asymptomatic cows in the Arnside outbreak and from one in the incident in Colorado supports earlier findings ${ }^{8}$ and raises the question of the prevalence of campylobacter infection in milk herds and the importance of this organism as a bovine pathogen. 
Work is needed on the place of such herds in the ecology of campylobacters, the endemicity of the infection within herds, and the factors leading to contamination of milk.

We believe that the evidence points to thermophilic Campylobacter $s p$ being an occasional but important contaminant of milk, which, under certain circumstances, may give rise to considerable outbreaks of enteritis in man. As with salmonella contamination it is probably only important where unpasteurised milk is consumed, but so long as there is a public demand for unpasteurised milk and the law allows such milk to be widely distributed, we believe that there is a risk that outbreaks will continue to occur.

We express our gratitude to all concerned in investigating these outbreaks and particularly to the Environmental Health Department, South Lakeland District Council, Cumbria; the Environmental Health Division, City of Bradford Metropolitan Council; and the laboratory staff at Preston and Leeds Public Health Laboratories and the Department of Medical Microbiology, Bradford Royal Infirmary.
We also thank Dr M B Skirrow and the laboratory staff at Worcester Royal Infirmary for biotyping the isolates.

Requests for reprints should be addressed to: Dr D A Robinson, Public Health Laboratory, Withington Hospital, Manchester M20 8LR.

\section{References}

1 Pether, J V S, Communicable Disease Report 1978, No 20, Public Health Laboratory Service (unpublished).

${ }^{2}$ Mortality and Morbidity Weekly Report, 1978, 27, 27.

3 Skirrow, M B, British Medical fournal, 1977, 2, 9.

4 Pinegar, J A, and Padmore, $\mathrm{H}$, personal communication.

5 Jones, F S, and Little, R B, fournal of Experimental Medicine, 1931, 53, 853.

${ }^{6}$ Levy, A J, Yale fournal of Biology and Medicine, 1946, 18, 243

${ }^{7}$ Park, C, personal communication.

8 Jones, F S, Orcutt, M, and Little, R B, fournal of Experimental Medicine, $1931,53,835$.

(Accepted 16 March 1979)

\title{
Pressure on the tracheal mucosa from cuffed tubes
}

\author{
JULIAN M LEIGH，J P MAYNARD
}

British Medical fournal, 1979, 1, 1173-1174

\section{Summary and conclusions}

During cuffed intubation, damage to the trachea is least likely when the lateral wall pressure exerted by the cuff does not exceed the mean capillary perfusion pressure of the mucosa. A study was carried out of eight different types of endotracheal tubes. At the seal point the traditional red rubber tube and the armoured latex and Softway tubes exerted pressures above the mean systemic arterial pressure. Although the Portex and Mallinckrodt tubes exerted pressures close to the mean capillary perfusion pressure, much higher pressures resulted if they were overinflated. The Lanz tube, however, with its over-pressure safety balloon, maintained a lateral wall pressure below the mean capillary perfusion pressure even when inflated considerably beyond the seal point.

Endotracheal cuffs are often overinflated in clinical practice. Since cuff-induced tracheal damage is most influenced by the lateral wall pressure, these results suggest that the use of Lanz-type tubes should be mandatory in intensive care units or when a cuffed tracheostomy tube is required and they should also be considered for use in more routine anaesthetic practice.

\section{Introduction}

Excessive pressure exerted on the tracheal mucosa is an avoidable factor that has been implicated as a cause of damage after intubation of the trachea with cuffed tubes. The relatively stiff, traditional, low-volume rubber cuff requires a pressure above systolic blood pressure to make it expand to meet the tracheal wall. Part of this pressure is transmitted to the tracheal mucosa once contact has been made. Mucosal damage, cartilaginous necrosis, and eventual tracheal stenosis may result from using such low-volume, high-pressure cuffs. To prevent this several high-volume, low-pressure cuffs have been developed over the past few years, though these are still apt to exert excessive pressure on the tracheal wall when overinflated or when nitrous oxide diffuses into them from an anaesthetic mixture.

To mitigate this a revolutionary principle has been incorporated into the design of the Lanz tube, ${ }^{1}$ which has only recently become available in Britain. This new tube has a high-volume, low-pressure cuff but the innovation is that the pilot balloon has a pressure-control valve and is a high-capacity latex structure. Thus any overinflation merely results in an expansion of the latex balloon so that the pressure within the system remains constant. Since in clinical practice all endotracheal cuffs probably tend to be overinflated, we consider this concept to be so important that we have evaluated the Lanz tube against other available equipment both in vitro and in vivo.

\section{Methods}

An East Radcliffe ventilator was used to ventilate a BOC model lung via an adult model trachea (National Catheter Corporation). At constant settings of the ventilator and model lung eight different types of No 9 tubes were inserted into the model trachea after lubrication with $\mathrm{KY}$ jelly. The following tubes were tested: Portex Blue Line, Kamen-Wilkinson, Lanz, armoured latex, Mallinckrodt, Portex Profile, red rubber, and Softway. The cuff was inflated and the seal point determined with great care. The airway pressure, intracuff pressure, and lateral wall pressure exerted by the cuff on the model trachea were determined at the seal point. The pressures were sensed using Bentley Trantec model 800 transducers: the airway pressure via a $T$ junction; the intracuff pressure via a miniature $T$ junction in the pilot-balloon line; and the lateral wall pressure via a flat balloon inserted between the cuff and the model trachea wall. This balloon had a diameter of $17 \mathrm{~mm}$ and maximal thickness (at its centre) of $3 \mathrm{~mm}$. The display and recordings were achieved using a Spacelabs (Novamed Ltd) type 3204 Alpha 9 display unit and model 1060 hot-stylus recorder. In each experiment a constant tidal volume was verified using an electronic Wright respirometer (BOC).

\section{Results}

In-vitro studies-Figure 1 summarises the results of the in-vitro experiments. Only the Kamen-Wilkinson tube lies to the left of the 